\title{
Effect of the Grain Boundary Thermal Expansion Coefficient on the Fracture Toughness in Silicon Nitride
}

\author{
Irene M. Peterson ${ }^{*}$ and Tseng-Ying Tien \\ Department of Materials Science and Engineering, The University of Michigan, Ann Arbor, Michigan 48109
}

\begin{abstract}
The effect of thermal expansion mismatch stress between silicon nitride and different grain boundary phases on the fracture toughness of silicon nitride was investigated. Different sintering aids in the Y-Mg-Si-Al-O-N system produced silicon nitride specimens with very similar microstructures but different grain boundary phase compositions and different values of fracture toughness. The fracture toughness of the silicon nitride increased as the thermal expansion coefficient of the grain boundary phase increased. The presence of tensile residual stress at the grain boundary caused by thermal expansion mismatch between the silicon nitride and the grain boundary phase enhanced crack deflection and grain bridging.
\end{abstract}

\section{Introduction}

$\mathrm{B}$ ECAUSE of its strong covalent bonding and slow diffusion rates, silicon nitride is very difficult to densify without a sintering aid. Sintering aids affect the properties of the silicon nitride ceramic in two ways: by their effect on microstructure development and by the properties of the grain boundary phase formed by the sintering aids. There is a large amount of literature on the effect of grain diameter and aspect ratio on fracture toughness. ${ }^{1-3}$ However, several authors have observed that silicon nitride samples which were sintered with different sintering aids had the same microstructure but drastically different values of fracture toughness. ${ }^{4}$ The differences in fracture toughness were attributed to differences in the grain boundary phase. The thermal expansion coefficient, elastic properties and toughness of the grain boundary phase, and the bond strength between the matrix and the grain boundary would be expected to affect the crack path. Despite the importance of the behavior of the grain boundary phase, the effect of the grain boundary phase on crack morphology and fracture toughness is poorly understood. The purpose of this study was to determine the effect of residual stress on crack path and fracture toughness in silicon nitride. To accomplish this, sintering aids were used which produced similar microstructures, but which produced grain boundary glasses with different thermal expansion coefficients.

In order to determine the thermal expansion coefficients of the grain boundary phases, model glasses with the same composition as the grain boundary phase were prepared. The compositions of the amorphous grain boundary phase can be found from the composition of the sintering liquid. The solid/liquid equilibria relevant to many of the systems in this study have been determined by other authors. The solid/liquid phase equilibria in the $\mathrm{Mg}, \mathrm{Si}, \mathrm{Al} / \mathrm{O}, \mathrm{N}$ system were determined by Hayashi

R. Raj-contributing editor

Manuscript No. 193343. Received August 5, 1994; approved April 2, 1995.

Presented at the 96th Annual Meeting of the American Ceramic Society, Indianapolis, IN, April 25-27, 1994 (Paper No. Sill-3-94).

Supported by the U.S. Department of Energy Office of Transportation Technologies Advanced Materials Development Program, through Oak Ridge National Laboratories Contract No. DE-AC05-84OR2140.

"Member, American Ceramic Society. and Tien, ${ }^{5}$ Bonnell, ${ }^{6}$ and Hwang. ${ }^{7}$ The solid/liquid equilibria in the $\mathrm{Y}, \mathrm{Si}, \mathrm{Al} / \mathrm{O}, \mathrm{N}$ system were determined by $\mathrm{Wisnudel}^{8}$ and Huang and Tien. ${ }^{9}$ The compositions of the sintering liquid in the $\mathrm{Y}, \mathrm{Mg}, \mathrm{Si}, \mathrm{Al} / \mathrm{O}, \mathrm{N}$ system were determined as part of this study.

The compositions of some of the crystalline grain boundary phase in equilibrium with silicon nitride have been reported. Subsolidus phase relationships in the $\mathrm{Si}, \mathrm{Al}, \mathrm{Mg} / \mathrm{O}, \mathrm{N}$ system were reported by Nunn et al. ${ }^{10}$ Both cordierite and $\mathrm{N}$ phase are compatible with silicon nitride. ${ }^{10}$ Subsolidus phase relationships in the $\mathrm{Si}, \mathrm{Al}, \mathrm{Y} / \mathrm{O}, \mathrm{N}$ system were reported by Naik and Tien ${ }^{11}$ and by Sun et al. ${ }^{12}$ Both $\mathrm{YAG}$ and $\mathrm{Y}_{2} \mathrm{Si}_{2} \mathrm{O}_{7}$ are compatible with silicon nitride. The thermal expansion coefficients of crystallized $\mathrm{Y}, \mathrm{Mg}, \mathrm{Si}, \mathrm{Al} / \mathrm{O}, \mathrm{N}$ compositions were measured for this study.

The effect of the grain boundary phase on toughness and crack propagation was demonstrated by Tanaka et al., ${ }^{13}$ who densified silicon nitride without additional sintering aids. They reported a fracture toughness of $3.0 \mathrm{MPa} \cdot \mathrm{m}^{0.5}$ for their fully dense material. The addition of $20 \mathrm{vol} \% \mathrm{Si}_{3} \mathrm{~N}_{4}$ whiskers raised the fracture toughness only slightly, to $3.5 \mathrm{MPa} \cdot \mathrm{m}^{0.5}$. Their photo of the crack path revealed nearly transgranular fracture, with little sign of crack bridging, deflection, or pullout by the whiskers. Therefore the whiskers did not contribute much to the fracture toughness. Clearly, elongated grains are useful only if the fracture path is primarily intergranular.

Bridging grains are formed when the crack is deflected around the silicon nitride grain, leaving the grain intact. The formation of bridging grains is affected by the presence of residual stresses in the material. Residual stresses caused by thermal expansion mismatch between the grain boundary phase and the silicon nitride interact with the crack tip. For smooth grains, tensile stress in the grain boundary phase would be expected to draw the crack along the weaker grain boundary phase, enhance debonding, and lead to intergranular fracture. ${ }^{14}$ Compressive stress in the grain boundary phase would be expected to limit debonding and lead to transgranular fracture. The use of thermal expansion mismatch stresses to improve fracture toughness was demonstrated by Taya et al. in a $\mathrm{SiC} /$ $\mathrm{TiB}_{2}$ composite. ${ }^{15}$ Local residual stresses were also observed to affect the crack path in a SiC/glass composite. ${ }^{16}$

The conditions for crack deflection along a fiber were determined by Evans and He. ${ }^{17}$ The crack will deflect if

$$
G_{\mathrm{i}} / G_{\mathrm{f}}>T_{\mathrm{i}} / T_{\mathrm{f}}
$$

where $G_{\mathrm{i}}=$ the crack energy release rate along the interface, $G_{\mathrm{f}}=$ the crack energy release rate through the fiber, $T_{i}=$ the fracture energy of the interface, and $T_{\mathrm{f}}=$ the fracture energy of the fiber.

The ratio of the critical energy release rates depends on the alignment between the loading stress and the fibers, and the elastic properties of the fiber and interface. The $G_{\mathrm{i}} / G_{\mathrm{f}}$ ratios were calculated as a function of the angle of crack deflection by Evans and Marshall ${ }^{18}$ for the case where the elastic properties of the fiber and matrix were the same. The analysis was extended by $\mathrm{He}$ and Hutchinson ${ }^{19}$ to account for an interface between materials with different elastic constants. The elastic constants of the material were taken into account through Dundar's parameter, $\alpha_{\text {Dundar }}$ : 


$$
\alpha_{\text {Dundar }}=\frac{G_{1}\left(1-v_{2}\right)-G_{2}\left(1-v_{1}\right)}{G_{1}\left(1-v_{2}\right)+G_{2}\left(1-v_{1}\right)}
$$

where $G_{1}=$ shear modulus of the silicon nitride, $G_{2}=$ shear modulus of the glass, $v_{1}=$ Poisson's ratio of the silicon nitride, and $v_{2}=$ Poisson's ratio of the glass.

The ratio of critical energy release rates, $G_{\mathrm{i}} / G_{\mathrm{f}}$ was calculated as a function of the angle of deflection and $\alpha_{\text {Dundar }}$ by $\mathrm{He}$ and Hutchinson. ${ }^{19}$

Local residual stresses change the fracture resistance of the fiber and interface according to models proposed by Evans et al..$^{20}$ and Cutler and Virkar. ${ }^{21}$ When the silicon nitride is under compressive stress, the fracture resistance of the silicon nitride particles increases:

$$
\begin{aligned}
& K_{\mathrm{R}}=K_{\mathrm{I0}}+2 \sigma_{\mathrm{sn}} \sqrt{\frac{2 \lambda}{\pi}} \\
& \Delta K_{\mathrm{q} \mathrm{sn}}=2 \sigma_{\mathrm{sn}} \sqrt{\frac{2 \lambda}{\pi}}
\end{aligned}
$$

where $\sigma_{\text {sn }}=$ local average compressive stress in the silicon nitride, $\lambda=$ distance over which stress is exerted (grain diameter), $K_{\mathrm{R}}=$ fracture resistance for silicon nitride/particle composite, $K_{\mathrm{I} 0}=$ fracture toughness of silicon nitride without particles, and $\Delta K_{\mathrm{qsn}}=$ change in critical stress intensity factor in the silicon nitride caused by residual stress.

The fracture resistance of the glass decreases because the glass is under tensile residual stress. If the silicon nitride is under compression and the glass is under tension, the relative fracture energy ratio would decrease, which would promote crack deflection:

$$
\begin{aligned}
& T=\frac{K^{2}}{E} \\
& \frac{T_{\mathrm{i}}}{T_{\mathrm{sn}}}=\left\{\frac{\left[K_{\mathrm{IOi}}\right]^{2}-\left[\Delta K_{\mathrm{qi}}\right]^{2}}{\left[K_{\mathrm{IOsn}}\right]^{2}+\left[\Delta K_{\mathrm{qsn}}\right]^{2}}\right\} \frac{E_{\mathrm{sn}}}{E_{\mathrm{i}}}
\end{aligned}
$$

where $E_{\mathrm{sn}}$ and $E_{\mathrm{i}}$ are Young's moduli of the silicon nitride and glass. The effects of residual stresses on apparent fracture resistance had been observed in tests of crack propagation along bimaterial interfaces by Charalambides et al..$^{22} \mathrm{~A}$ residual stress of $10 \mathrm{MPa}$ at the interface of a sandwich specimen changed the measured fracture resistance from the intrinsic material value of $2 \mathrm{~J} \cdot \mathrm{m}^{-2}$ to $7 \mathrm{~J} \cdot \mathrm{m}^{-2}$.

There are many equations in the literature to calculate residual stresses. One widely used one is based on Eshelby's inclusion theory ${ }^{23}$ as arranged by Hsueh ${ }^{24}$ and Taya et al.:.$^{15}$

$$
\sigma_{\mathrm{sn}}=\left(\alpha_{\mathrm{sn}}-\alpha_{\mathrm{g}}\right) \Delta T\left[\frac{1-2 v_{\mathrm{sn}}}{E_{\mathrm{sn}}}+\frac{1+f_{\mathrm{sn}}+\nu_{\mathrm{g}}\left(1-4 f_{\mathrm{sn}}\right)}{2 E_{\mathrm{g}}\left(1-f_{\mathrm{sn}}\right)}\right]^{-1}
$$

and

$$
\sigma_{\mathrm{g}}=-\frac{f_{\mathrm{sn}}}{1-f_{\mathrm{sn}}} \sigma_{\mathrm{sn}}
$$

where $\sigma_{\mathrm{sn}}$ and $\sigma_{\mathrm{g}}$ are the stresses in the silicon nitride and glass matrix, $\alpha_{s n}$ and $\alpha_{\mathrm{g}}$ are the thermal expansion coefficients of the silicon nitride and glass matrix, $\Delta T$ is the difference in temperature over which the stresses are locked in, $f_{\mathrm{sn}}$ is the volume fraction of the silicon nitride, $v_{\mathrm{sn}}$ and $\nu_{\mathrm{g}}$ are Poisson's ratios of the silicon nitride and glass, and $E_{\mathrm{sn}}$ and $E_{\mathrm{g}}$ are Young's moduli of the silicon nitride and glass.

The glass was assumed to be the continuous phase, and the particles are $\mathrm{Si}_{3} \mathrm{~N}_{4} . \Delta T$ was taken as the difference between the glass transition temperature of the grain boundary glass and room temperature, which was approximately $1000^{\circ} \mathrm{C}$.

Models developed by Becher ${ }^{25}$ and Swansson et al. ${ }^{26}$ for alumina relate fracture toughness to the presence of bridging grains behind the crack tip. The crack tip bridging stresses are determined by the size and shape of the silicon nitride grains, the residual stresses present in the material, and the details of the stress vs separation curve of the bridging grains. ${ }^{27}$ The models attribute the residual stresses to thermal expansion mismatch between grains of different orientations. ${ }^{27}$ Additional residual stresses are introduced by thermal expansion mismatch between the grain boundary phase and the silicon nitride.

According to Becher's model, the increase in fracture toughness caused by bridging grains can be expressed as

$$
\Delta K^{\mathrm{gb}}=\left[A^{\mathrm{gb}} \tau_{\mathrm{gb}} E^{\mathrm{c}} d / 2\left(1-v^{2}\right)\right]^{1 / 2}
$$

where $\Delta K^{\mathrm{g} b}=$ the increase in fracture toughness from bridging grains, $A^{\mathrm{gb}}=$ the area fraction of bridging grains, $\tau_{\mathrm{gb}}=$ the frictional sliding stess, $E^{\mathrm{c}}=$ Young's modulus of the composite, $d=$ grain length, $v=$ Poisson's ration of the composite.

According to both models, the fracture toughness of the silicon nitride is expected to increase linearly as the area fraction of bridging grains increases.

\section{Experimental Procedure}

\section{(1) Silicon Nitride}

Silicon nitride samples with 5,10 , and 15 vol\% of four different sintering aids were prepared. The sintering aids were combinations of the commonly used sintering aids cordierite $\left(\mathrm{Mg}_{2} \mathrm{Al}_{4} \mathrm{Si}_{5} \mathrm{O}_{18}\right)$ and $\mathrm{YAG}\left(\mathrm{Y}_{3} \mathrm{Al}_{5} \mathrm{O}_{12}\right)$. The compositions of the sintering aids are shown in Table $\mathrm{I}$.

The powders were attrition-milled with silicon nitride for $4 \mathrm{~h}$. A three-step firing schedule was used for the samples which contained 15 vol\% sintering aid, as shown in Table II. The samples were densified at $1640^{\circ} \mathrm{C}$ for $3 \mathrm{~h}$, then held at higher temperature to grow the grains, and then held at $1640^{\circ} \mathrm{C}$ for $2 \mathrm{~h}$ to reequilibrate the grain boundary phase.

To determine the effect of the volume fraction of grain boundary phase on the fracture toughness of silicon nitride, a set of samples with 5,10 , and $15 \mathrm{vol} \%$ of the four different additives was sintered at $1640^{\circ} \mathrm{C}$ for $3 \mathrm{~h}$.

The samples were cooled rapidly by turning off the power to the furnace. X-ray diffraction was used to determine the phases present, which were $\beta-\mathrm{Si}_{3} \mathrm{~N}_{4}$ and glass. The compositions of the grain boundary glasses were determined by the lever rule from the volume fraction of glass present in SEM photos of the microstructure, and compared to the compositions determined from the bulk glasses.

Some samples underwent further heat treatment for $15 \mathrm{~h}$ at $1250^{\circ}-1350^{\circ} \mathrm{C}$ to crystallize the grain boundary phase. X-ray diffraction was used to determine the phases present. The densities of the samples were measured using Archimedes' method.

The fracture toughness was measured by the indentation method with loads of $10 \mathrm{~kg}$. The fracture toughness was calculated using the equation of Anstis et al.:28

$$
K_{c}=0.016\left(\frac{E}{H}\right)^{2}\left(\frac{P}{c^{3 / 2}}\right)
$$

where $K_{c}$ is the fracture toughness, $E$ is Young's modulus, $H$ is the hardness, $P$ is the peak load on the Vickers indenter, and $c$ is the crack length from the center of the indent to one tip of the crack.

The microstructures and crack paths were examined using the SEM. When the elemental contrast in the SEM was insufficient to reveal the microstructure, the samples were etched in a

Table I. Compositions of Sintering Aids

\begin{tabular}{lcc}
\hline \multicolumn{3}{c}{ Sintering Aids } \\
\hline Composition & $\begin{array}{c}\text { Cordierite } \\
(\text { wt } \%)\end{array}$ & $\begin{array}{c}\text { YAG } \\
(\text { wt } \%)\end{array}$ \\
\hline C & 100 & 0 \\
$80 \mathrm{C} / 20 \mathrm{Y}$ & 80 & 20 \\
$60 \mathrm{C} / 40 \mathrm{Y}$ & 60 & 40 \\
$\mathrm{Y}$ & 0 & 100 \\
\hline
\end{tabular}


Table II. Sintering and Crystallization Schedules

\begin{tabular}{cccc}
\hline Name & \multicolumn{1}{c}{ Step 1 } & Step 2 & Step 3 \\
\hline $1640(3)$ & $1640^{\circ} \mathrm{C} 3 \mathrm{~h}$ & & \\
$1800(3)$ & $1640^{\circ} \mathrm{C} 3 \mathrm{~h}$ & $1800^{\circ} \mathrm{C} 3 \mathrm{~h}$ & $1640^{\circ} \mathrm{C} 2 \mathrm{~h}$ \\
$1840(1)$ & $1640^{\circ} \mathrm{C} 3 \mathrm{~h}$ & $1840^{\circ} \mathrm{C} 1 \mathrm{~h}$ & $1640^{\circ} \mathrm{C} \mathrm{h}$ \\
$1840(3)$ & $1640^{\circ} \mathrm{C} 3 \mathrm{~h}$ & $1840^{\circ} \mathrm{C} 3 \mathrm{~h}$ & $1640^{\circ} \mathrm{C} \mathrm{h}$ \\
$1840(6)$ & $1640^{\circ} \mathrm{C} 3 \mathrm{~h}$ & $1840^{\circ} \mathrm{C} 6 \mathrm{~h}$ & $1640^{\circ} \mathrm{C} \mathrm{h}$ \\
$1880(3)$ & $1640^{\circ} \mathrm{C} 3 \mathrm{~h}$ & $1880^{\circ} \mathrm{C} 3 \mathrm{~h}$ & $1640^{\circ} \mathrm{C} \mathrm{h}$ \\
\hline
\end{tabular}

molten salt solution for 15 to $30 \mathrm{~s}$. The distance between bridging grains was measured from the SEM photographs from five indentation cracks for each sample. The portions of the crack which showed space between the faces were examined for evidence of bridging grains. The cracks were photographed in segments of approximately $10 \mu \mathrm{m}$. Grains which remained intact across the crack face were immediately identified as bridging grains. Grains which had fractured at a distance from the crack plane and which showed evidence of being pulled out from their sockets were also considered to have been grain bridges.

The angle between the direction of crack propagation and a silicon nitride grain in its path determines whether the crack will propagate through the grain or be deflected. For a sample with a given composition, the crack would be deflected around the grain if the angle between the advancing crack and the grain was smaller than a critical angle. When the crack was deflected along a grain boundary, the angle between the macroscopic direction of the crack and the direction of the deflected segment was measured from SEM micrographs.

The mean angle of crack deflection and the maximum angle of crack deflection were measured. The entire lengths of five indentation cracks per sample were used to determine the angles of crack deflection. The cracks were divided into segments roughly $10 \mu \mathrm{m}$ in length.

The grain sizes of the samples were measured by the disintegration method. The samples were disintegrated in a molten salt bath of $\mathrm{KOH}: \mathrm{NaOH}$ in 1:1 molar ratio. To remove the surface grains, the samples were etched for $3 \mathrm{~min}$, rinsed in water, and placed in water in an ultrasonic cleaner for $5 \mathrm{~min}$. The sample was then etched again for an additional $3 \mathrm{~min}$, rinsed in water, and placed in water in the ultrasonic cleaner again for $5 \mathrm{~min}$. The loose grains from the second etching step were collected from the water by vacuum filtration. SEM photos of the collected grains were used to determine the average length and width of the grains. At least 100 grains were measured to determine the length and width values.

\section{(2) Composition and Thermal Expansion Coefficients of Grain Boundary Phases}

Glass compositions with the same ratios of oxide powders as in the sintering aids were prepared. Silicon nitride additions of 5,10 , and $15 \mathrm{wt} \%$ were added to the oxide powders. The $\mathrm{MgO}$, $\mathrm{Y}_{2} \mathrm{O}_{3}, \mathrm{Al}_{2} \mathrm{O}_{3}, \mathrm{SiO}_{2}$, and $\mathrm{Si}_{3} \mathrm{~N}_{4}$ powders were mixed by hand. The powders were melted under $10 \mathrm{~atm}$ nitrogen pressure at $1650^{\circ}-1700^{\circ} \mathrm{C}$ for $3 \mathrm{~h}$. The weight losses were $<1 \mathrm{wt} \%$. The maximum solubility of silicon nitride was determined using $\mathrm{X}$-ray diffraction and SEM. Electron probe microanalysis indicated that the cation ratios had not changed during melting.

Glass compositions as close to the solubility limit of $\mathrm{Si}_{3} \mathrm{~N}_{4}$ as possible were fabricated. X-ray diffraction and SEM showed that the glasses were completely amorphous; no $\mathrm{Si}_{3} \mathrm{~N}_{4}$ precipitates were detected. The thermal expansion coefficients of the glass compositions closest to the solubility limit of $\mathrm{Si}_{3} \mathrm{~N}_{4}$ were measured using an alumina rod dilatometer calibrated with a fused silica standard.

The glasses underwent a crystallization treatment at $1250^{\circ}-$ $1350^{\circ} \mathrm{C}$ for $15 \mathrm{~h}$. The thermal expansion coefficients of the devitrified samples were measured using an alumina rod dilatometer calibrated with a fused silica standard.

\section{Results}

\section{(1) Compositions and Thermal Expansion Coefficients of Glasses}

The compositions and thermal expansion coefficients (as determined from the model glasses) of the grain boundary glasses are shown in Table III. The compositions determined from the lever rule from the silicon nitride samples were the same as the compositions determined from the model glasses, and with those reported in earlier studies. ${ }^{5-9}$ The crystalline phases and their thermal expansion coefficients are listed in Table IV. The thermal expansion coefficient of the cordierite-rich glasses decreases on crystallization. The thermal expansion coefficient of the YAG-rich glasses increases on crystallization.

\section{(2) Effect of Thermal Expansion Coefficient of the Grain Boundary Phase on Crack Propagation in Silicon Nitride}

All the sintered samples were at least $99 \%$ dense. The microstructures produced using the different sintering aids in the $\mathrm{Y}, \mathrm{Mg}, \mathrm{Si}, \mathrm{Al} / \mathrm{O}, \mathrm{N}$ were very similar, as shown in Fig. 1 for samples sintered at $1640^{\circ} \mathrm{C}$ for $3 \mathrm{~h}$, followed by $1840^{\circ} \mathrm{C}$ for $1 \mathrm{~h}$ and $1640^{\circ} \mathrm{C}$ for an additional $2 \mathrm{~h}$. The average length and width of the silicon nitride grains are shown as a function of the amount of YAG in the sintering aids in Figs. 2(a) and (b). Note that the effect of sintering aid chemistry on grain morphology was negligible in this particular case, primarily because the grain growth temperature was very low and the volume fractions of liquid were the same. Therefore, any changes in fracture toughness for samples treated at the same temperature were not due to changes in grain shape or size. However, the crack paths are very different when different sintering aids are used,

Table IV. Thermal Expansion Coefficients of Crystalline Grain Boundary Phases

\begin{tabular}{cc}
\hline Phase & $\alpha\left(\times 10^{6} /{ }^{\circ} \mathrm{C}\right)$ \\
\hline YAG $\left(\mathrm{Y}_{3} \mathrm{Al}_{5} \mathrm{O}_{12}\right)$ & 8.0 \\
$\mathrm{~N}$-phase $\left(\mathrm{MgAl}_{2} \mathrm{Si}_{4} \mathrm{O}_{6} \mathrm{~N}_{4}\right)$ & $2.3^{*}$ \\
\hline *The thermal expansion coefficient of $\mathrm{N}$ phase was measured \\
by Nunn.
\end{tabular}

Table III. Grain Boundary Glass Compositions and Thermal Expansion Coefficients

\begin{tabular}{|c|c|c|c|c|c|}
\hline \multicolumn{5}{|c|}{ Composition (mol fraction) } & \multirow{2}{*}{$\left(\times 10^{\alpha} /{ }^{\circ} \mathrm{C}\right)^{*}$} \\
\hline $\mathrm{MgO}$ & $\mathrm{Y}_{2} \mathrm{O}_{3}$ & $\mathrm{Al}_{2} \mathrm{O}_{3}$ & $\mathrm{SiO}_{2}$ & $\mathrm{Si}_{3} \mathrm{~N}_{4}$ & \\
\hline 0.20 & 0 & 0.21 & 0.51 & 0.08 & 3.4 \\
\hline 0.18 & 0.03 & 0.24 & 0.46 & 0.09 & 3.7 \\
\hline 0.16 & 0.08 & 0.28 & 0.39 & 0.10 & 4.1 \\
\hline 0 & 0.25 & 0.42 & 0.08 & 0.25 & 4.6 \\
\hline
\end{tabular}




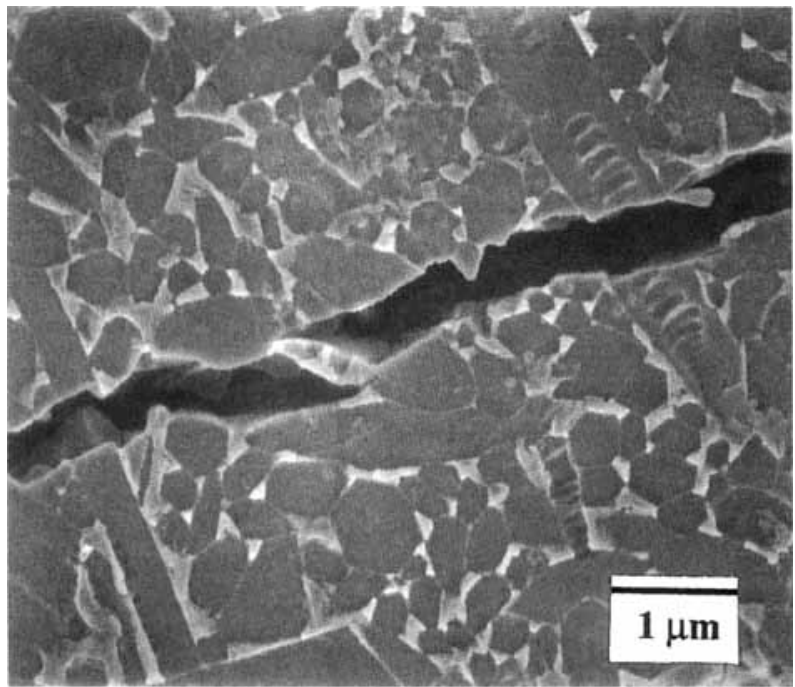

(a)

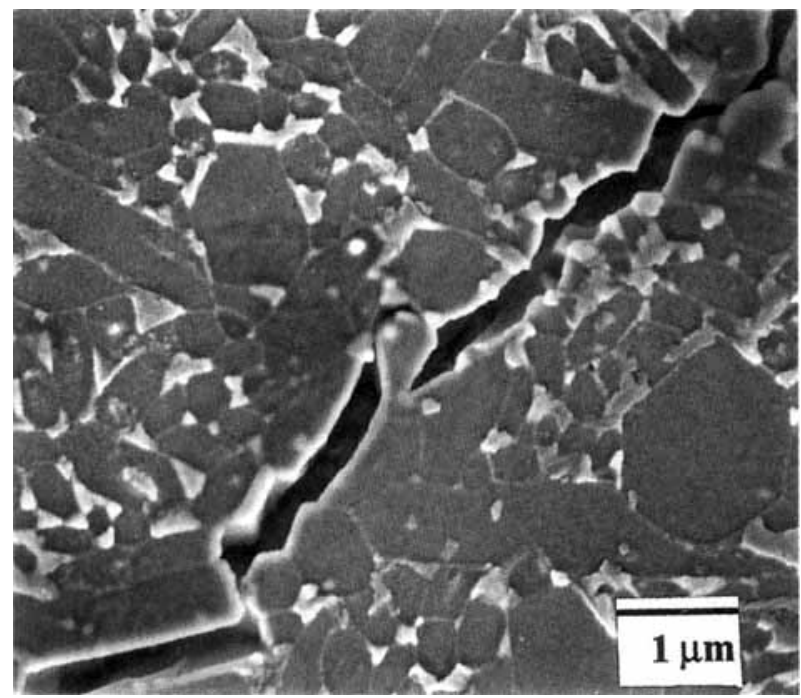

(b)

Fig. 1. (a) Microstructure and crack path in silicon nitride sintered with $15 \mathrm{vol} \%$ of $100 \mathrm{wt} \%$ cordierite. This sample was plasma etched. (b) Microstructure and crack path in silicon nitride sintered $15 \mathrm{vol} \%$ of $60 \mathrm{wt} \%$ cordierite $/ 40 \mathrm{wt} \%$ YAG. This sample was plasma etched.

as shown in Fig. 1. The sample sintered with cordierite alone shows a nearly straight crack path with almost no bridging grains. In contrast, the sample sintered with YAG shows crack deflection and bridging grains.

The fracture toughness would be expected to increase as the distance between bridging grains decreased and as the amount of crack deflection increased. As expected from the photos of the crack paths, the fracture toughness increased as the thermal expansion coefficient of the grain boundary phase increased, as shown in Fig. 3.

The fracture path was characterized by the distance between bridging grains and the angles of crack deflection. The distance between bridging grains was measured from the SEM photographs. The distance between grains decreased as the thermal expansion coefficient of the grain boundary phase increased, as shown in Fig. 4.

The mean and maximum angles of crack deflection were determined from the SEM micrographs. The grain size of the sample had only a small effect on the crack deflection angles, as shown in Fig. 5. The angles increased slightly as the grain size of the sample increased. The angles increased as the

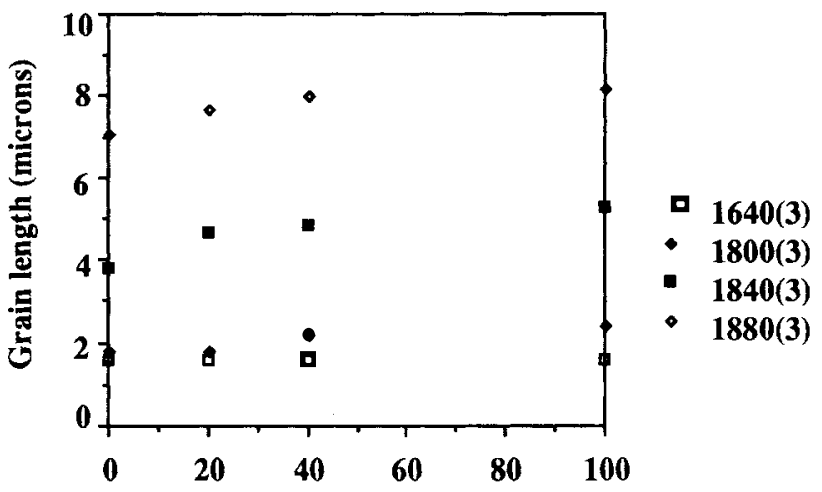

Wt \% YAG in 15 vol \% sintering aid

(a)

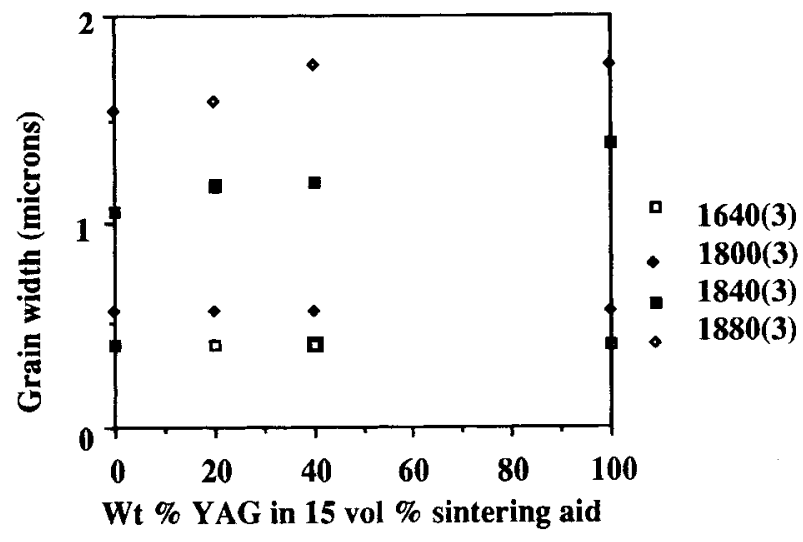

(b)

Fig. 2. (a) Effect of sintering aid composition on length of grains (b) Effect of sintering aid composition on width of grains.

thermal expansion coefficient of the grain boundary phase increased, as shown in Figs. 5(a) and (b). The range of mean crack deffection angles is the same as the range reported for $\mathrm{Si}_{3} \mathrm{~N}_{4}$ samples of similar toughness by Faber and Evans. ${ }^{29}$

The effect of crystallization on fracture toughness is shown in Fig. 6. When the thermal expansion coefficient of the grain boundary phase increased on crystallization, the fracture toughness increased upon crystallization. When the thermal expansion coefficient of the grain boundary phase decreased on crystallization, so did the fracture toughness.

\section{(2) Effect of Volume Fraction of Sintering Aid}

The grain length increased slightly as the amount of sintering aid increased, as shown in Fig. 7 for silicon nitride sintered with cordierite. The fracture toughness of the silicon nitride did not change when different volume fractions of magnesium aluminosilicate sintering aid were used. The fracture toughness increased slightly with increasing volume fraction of YAG, as shown in Fig. 8.

\section{Discussion}

The material properties used in the calculations in this section are listed in Table V. Using a modified version of Eshelby's inclusion method ${ }^{15}$ discussed earlier, the residual stress in the silicon nitride and in the grain boundary phase can be calculated from Eqs. (5) and (6), as shown in Fig. 9 for 15 vol\% of sintering aid. When the thermal expansion coefficient of the grain boundary phase is greater than that of the silicon nitride, both the tensile stress in the grain boundary and the compressive stress in the silicon nitride grains increase as the thermal expansion coefficient of the grain boundary phase increases. 


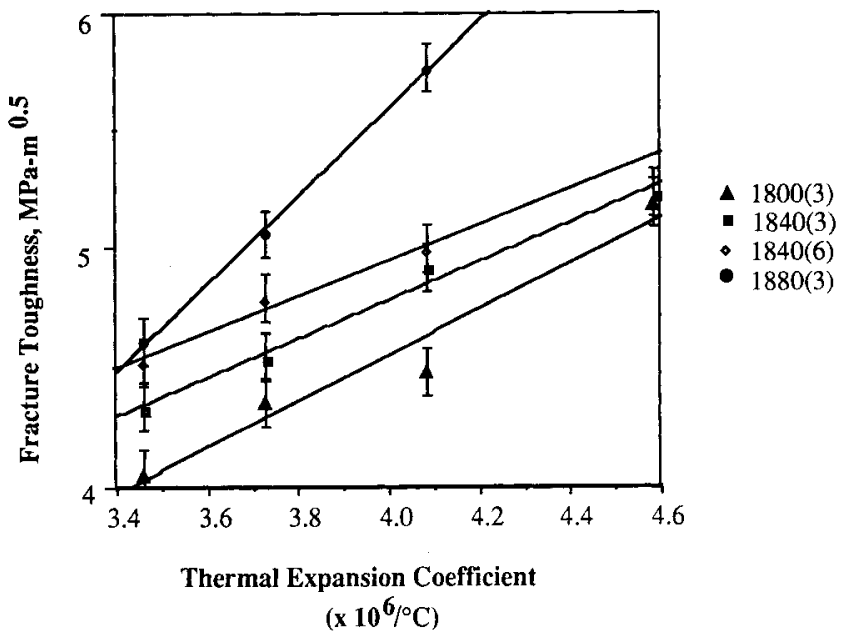

Fig. 3. Effect of thermal expansion coefficient of grain boundary phase on fracture toughness of silicon nitride sintered with $\mathrm{Y}_{2} \mathrm{O}_{3}-$ $\mathrm{Al}_{2} \mathrm{O}_{3}-\mathrm{MgO}-\mathrm{SiO}_{2}$ additives.

The residual stress in both phases can also be calculated as a function of the volume fraction of sintering aid, as shown in Fig. 10.

Tensile stress at the grain boundary and compressive stress in the silicon nitride grains promote crack deflection and the formation of bridging grains. The expected $T_{\mathrm{i}} / T_{\mathrm{f}}$ ratio was estimated (roughly) as a function of residual stress using Eq. (4) and the material properties listed in Table V. The distance over which stress was exerted was interpreted as the average grain diameter for silicon nitride. The initial toughness value of the aluminosilicate glass was taken as $0.9 \mathrm{MPa} \cdot \mathrm{m}^{0.5} .{ }^{28}$ The initial toughness of silicon nitride was taken as the single-crystal value of $2.0 \mathrm{MPa} \cdot \mathrm{m}^{0.5} .{ }^{13}$ The distance over which stress was exerted was interpreted as the average diameter of the silicon nitride grain. Since the maximum angle of crack deflection occurs when $T_{\mathrm{j}} / T_{\mathrm{f}}=G_{\mathrm{i}} / G_{\mathrm{f}}$, the predicted maximum angles of deflection can be found from the calculated $T_{\mathrm{i}} / T_{\mathrm{f}}$ ratios and the calculated Dundar's parameter, $\alpha_{\text {Dundar }}$. The value of $\alpha_{\text {Dundar }}$ was calculated as 0.5 . The critical angle of deflection was found from the graphs in He and Hutchinson's paper. ${ }^{19}$ The calculated critical angle of deffection is compared to the measured critical angle of deflection in Fig. 11. These calculations were performed to demonstrate that the change in crack deflection angle follows the trends expected from theory; no further significance is implied.

The fracture of grains which become bridges depends on the fracture of grains which intersect the crack at an angle favorable

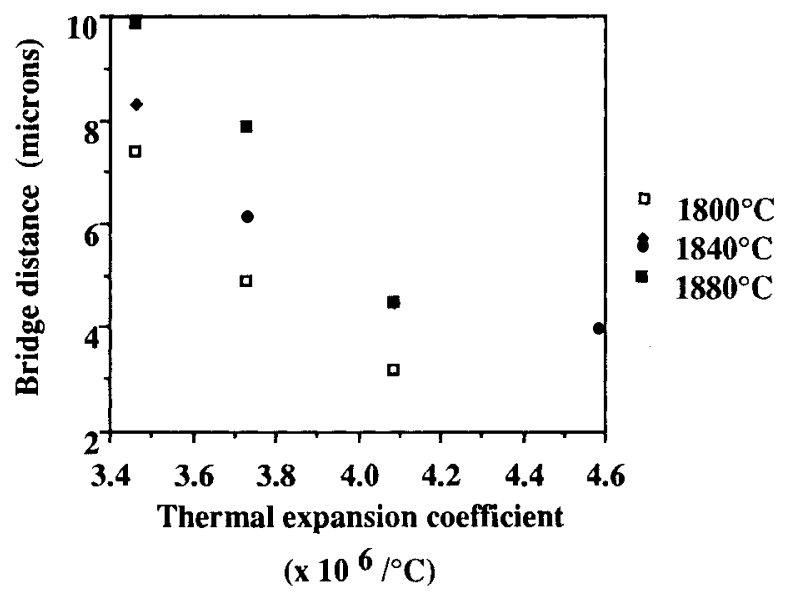

Fig. 4. Effect of thermal expansion coefficient on distance between bridging grains.

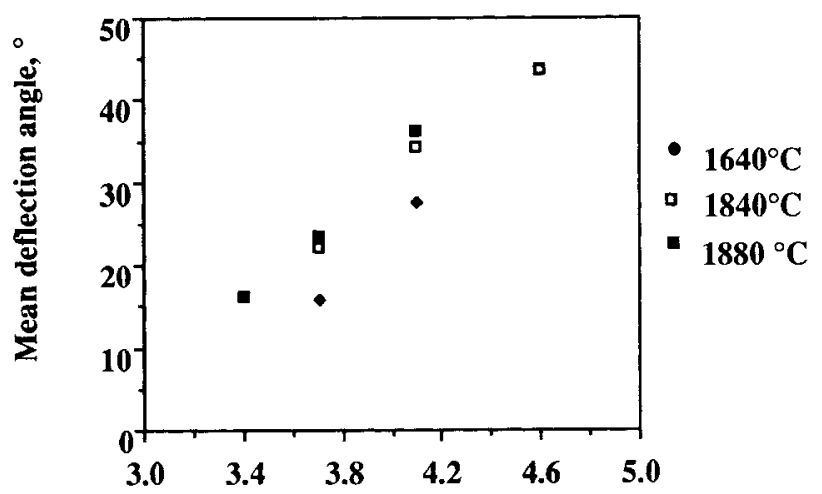

Thermal expansion coefficient

$\left(\times 10^{6} /{ }^{\circ} \mathrm{C}\right)$

(a)

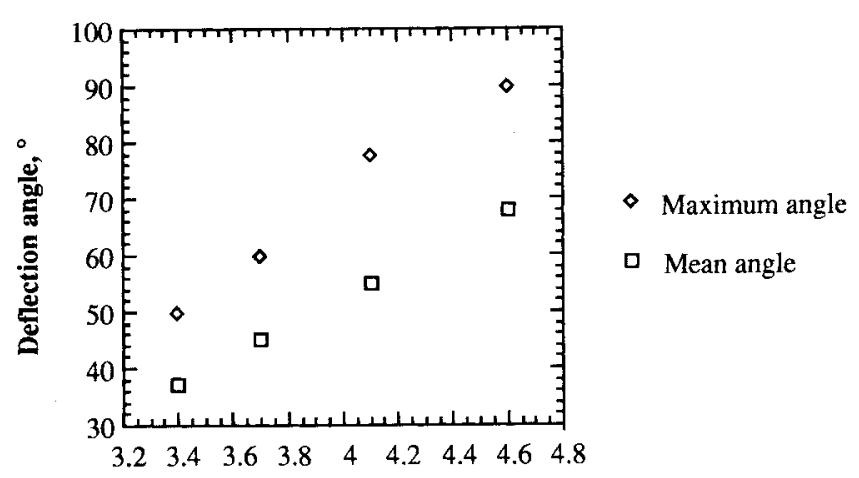

Thermal expansion coefficient

$\left(\times 10^{6} /{ }^{\circ} \mathrm{C}\right)$

(b)

Fig. 5. (a) Effect of sintering temperature and thermal expansion coefficient on mean crack deflection angle. (b) Effect of thermal expansion coefficient on maximum crack deflection angle (sintering step 2 at $1840^{\circ} \mathrm{C}$ for $3 \mathrm{~h}$ ).

for crack deflection. The linear fraction of the crack which was bridged is $l / d$, where $l$ is the grain diameter and $d$ is the distance between bridging grains. The linear fraction of the crack which was bridged increased linearly as the fraction of grains expected to intersect the crack at an angle less than the critical angle increased, as shown in Fig. 12 for silicon nitride sintered with combinations of cordierite and YAG.

The area fraction of bridging grains, $A_{\mathrm{gb}}$, can be estimated from the grain diameter and the distance between bridging grains: ${ }^{27}$

$$
A_{\mathrm{gb}}=\frac{l^{2}}{2 d^{2}}
$$

If a sample was broken in half and the fracture surface was examined, the fraction of the fracture surface which consisted of broken grain bridges would be the area fraction of bridging grains. In the samples in this study, the area fraction is just a mathematical convenience, since only the linear portion of the crack which is bridged can be measured. Figure 13 shows the linear increase in fracture toughness with the area fraction of bridging grains, in agreement with theory. ${ }^{25,27}$ For modeling purposes, it should be possible to predict the area fraction of bridging grains from the predicted maximum deflection angle and the grain diameter.

Changes in the chemistry of the glass have also been reported to change crack deflection angles by altering the intrinsic bonding strength of silicon nitride/glass interface, even in the 


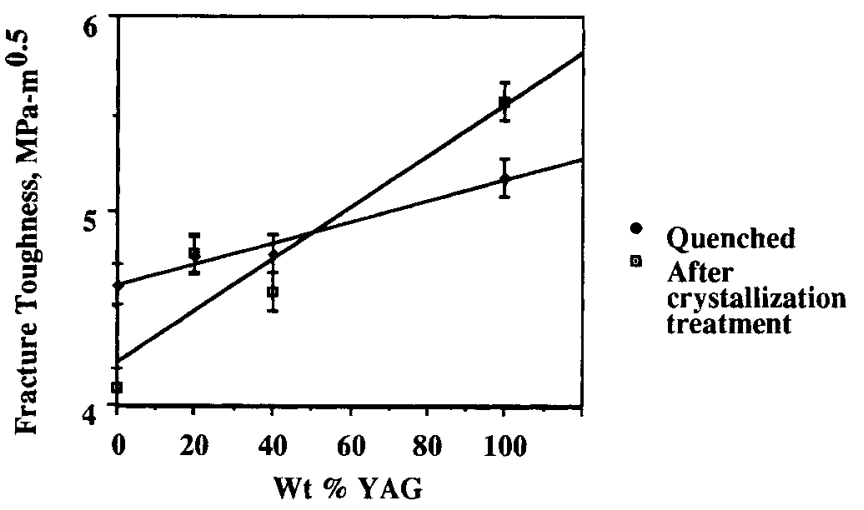

in cordierite/YAG sintering aid

Fig. 6. Effect of crystallization on fracture toughness.

absence of residual stress effects. ${ }^{30}$ However, the differences in chemistry between the first three grain boundary phase compositions shown in Table III are mostly caused by substitution of cations which are not directly involved in bonding across the interface. Therefore, the effect of the change in chemistry on the interfacial bond strength is expected to be relatively small for the three samples which contain cordierite in the sintering aid.

The changes which occur in fracture toughness after crystallization of the grain boundary phase can't be attributed entirely to changes in the thermal expansion coefficient of the grain boundary phase. Some of the change in fracture toughness after crystallization may be due to the stresses or porosity arising from volume changes which occur on crystallization.

According to earlier studies, both YAG and N-phase have higher densities than their respective oxynitride glasses. The density of the grain boundary phase in the $\mathrm{Mg}, \mathrm{Si}, \mathrm{Al} / \mathrm{O}, \mathrm{N}$ samples increases from the density of the glass at $2.6 \mathrm{~g} / \mathrm{cm}^{3}$ to the density of N-phase, which is $2.9 \mathrm{~g} / \mathrm{cm}^{3}$, an increase of $11 \%{ }^{31}$ The density of the grain boundary phase in the Y,Si,Al/O,N samples increased from the density of the glass, at $3.9 \mathrm{~g} / \mathrm{cm}^{3}$ to the density of $\mathrm{Y}_{3} \mathrm{Al}_{5} \mathrm{O}_{12}$, at $4.55 \mathrm{~g} / \mathrm{cm}^{3}$, an increase in density of almost $17 \%$. The volume changes can be accommodated by viscous flow of the grain boundary phase during crystallization, by solution/precipitation of the silicon nitride grains during crystallization, or by the development of pores in the grain boundary phase. ${ }^{32}$ Extensive crystallization would not have been possible unless most of the stresses produced during crystallization were relieved. ${ }^{32}$ Nunn reported that small shrinkage pores appeared in the grain boundary phase after crystallization in samples of $\beta^{\prime}$-SiAION sintered with cordierite additives. ${ }^{31}$ Shrinkage pores have also been reported in the corners of the

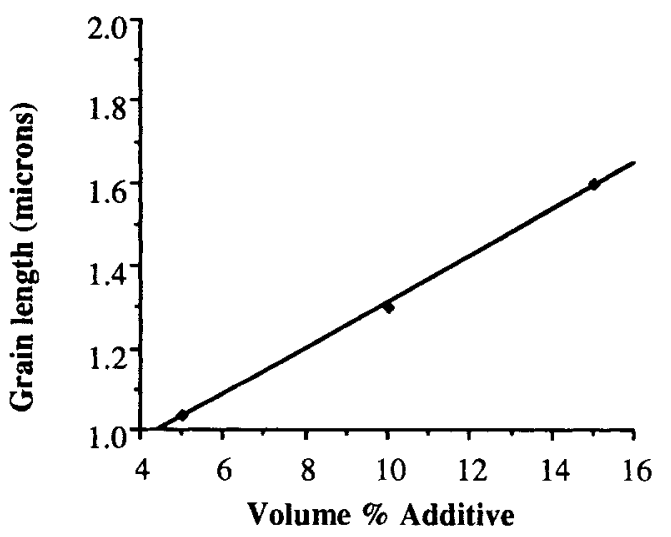

Fig. 7. Effect of small volume fractions of cordierite additive on length of $\mathrm{Si}_{3} \mathrm{~N}_{4}$ grains.

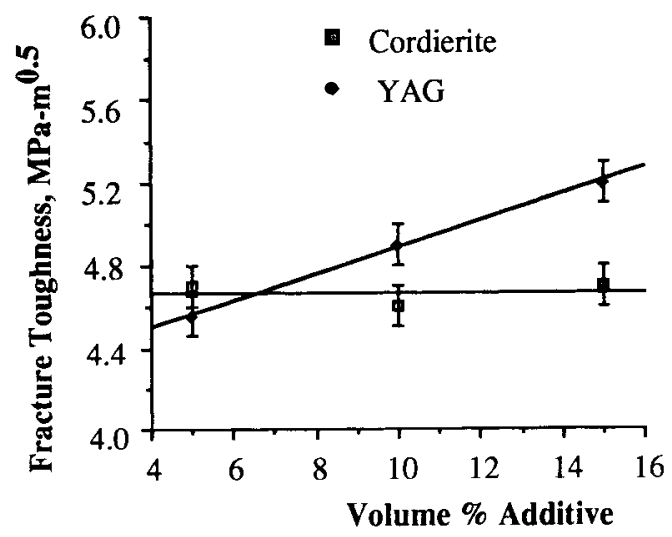

Fig. 8. Effect of volume fraction additive on fracture toughness of silicon nitride.

grain boundary triple points following crystallization treatments in samples of $\beta-\mathrm{Si}_{3} \mathrm{~N}_{4}$ sintered with yttria and strontia. ${ }^{33}$ SEM examination of the samples in this study did not reveal any pores in the grain boundary pockets. If there were pores, they may have been too small to detect by SEM.

Although the density of the grain boundary phases increased during crystallization in all of the samples, the fracture toughness increased only in the samples which had the highest volume fraction of YAG and decreased in others. Since the thermal

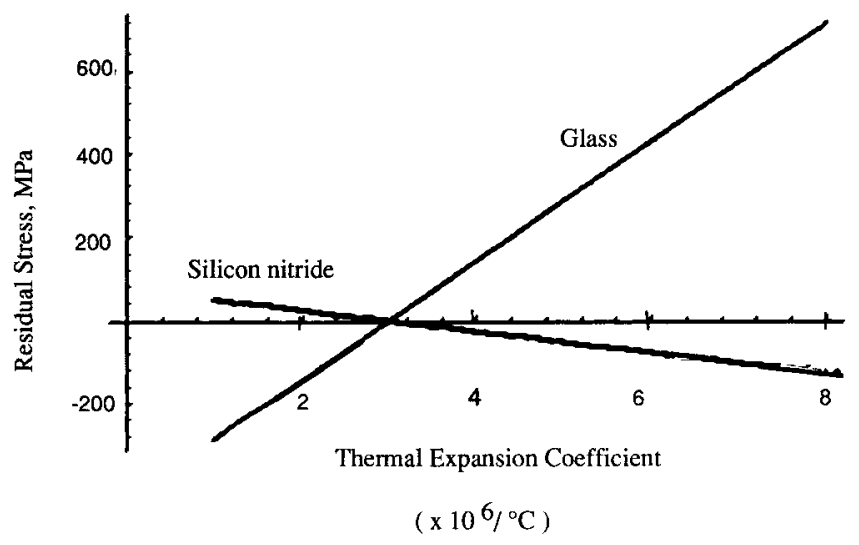

Fig. 9. Residual stress as a function of thermal expansion coefficient of the grain boundary phase for $\mathrm{Si}_{3} \mathrm{~N}_{4}$ containing 15 vol\% grain boundary phase.

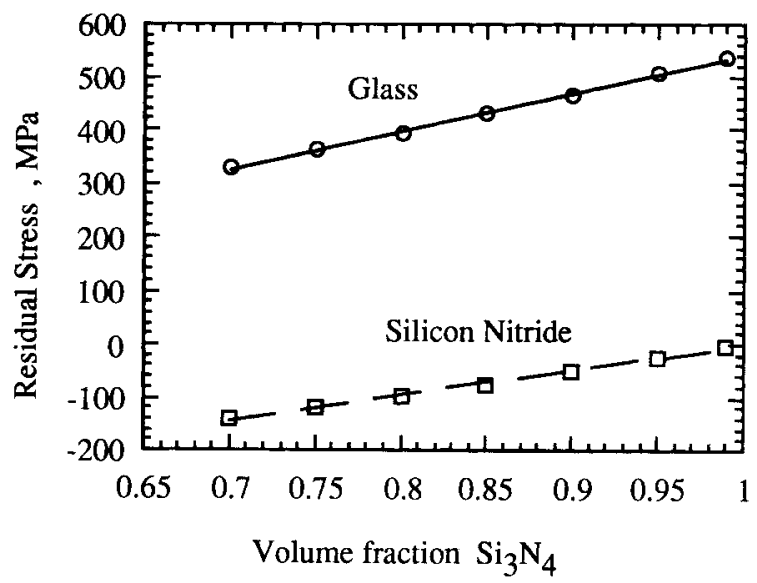

Fig. 10. Residual stress as a function of the volume fraction of grain boundary phase. Thermal expansion coefficient of the grain boundary phase $=6 \times 10^{-6} /{ }^{\circ} \mathrm{C}$ 
Table V. Elastic Properties Used in Calculations

\begin{tabular}{lcc}
\hline & Silicon nitride & Glass \\
\hline$E(\mathrm{GPa})$ & 300 & 100 \\
$v$ & 0.3 & 0.3 \\
$K_{0}\left(\mathrm{MPa} \cdot \mathrm{m}^{1 / 2}\right)$ & 2.0 & 0.9 \\
\hline
\end{tabular}

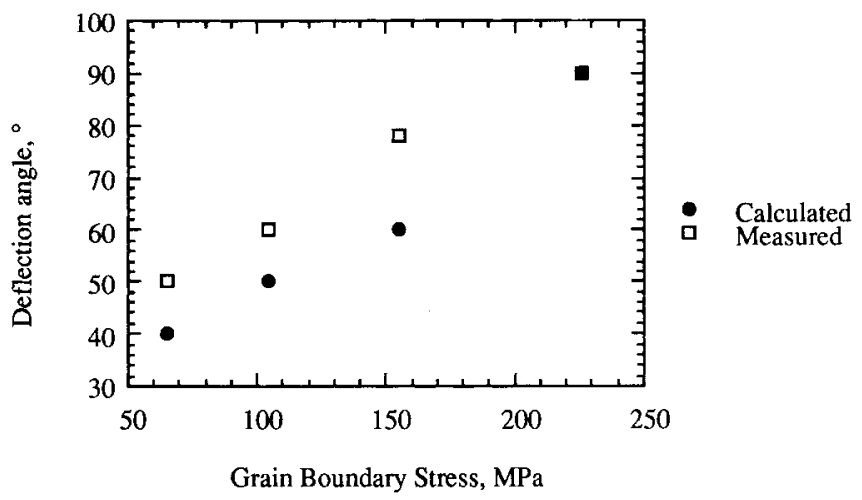

Fig. 11. Measured maximum deflection angles and calculated deflection angles.

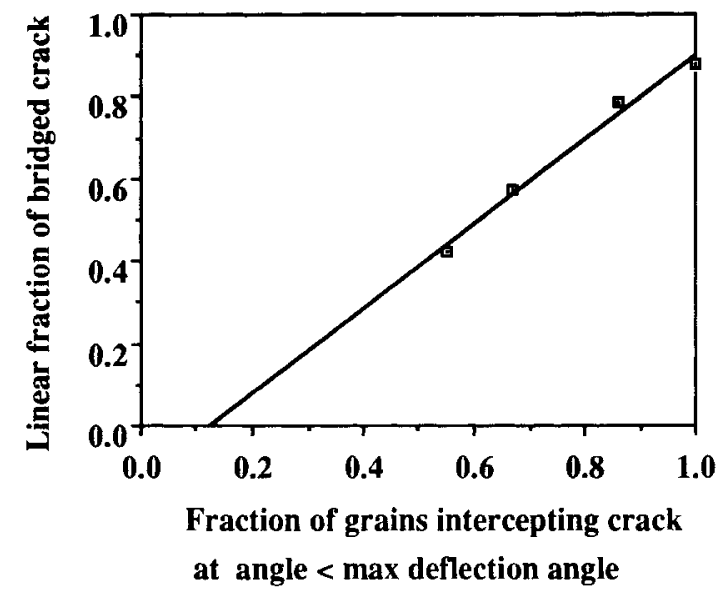

Fig. 12. Linear fraction of crack which is bridged increases as the fraction of grains oriented favorably for deflection increases (sintering step 2 at $1840^{\circ} \mathrm{C}$ for $3 \mathrm{~h}$ ).

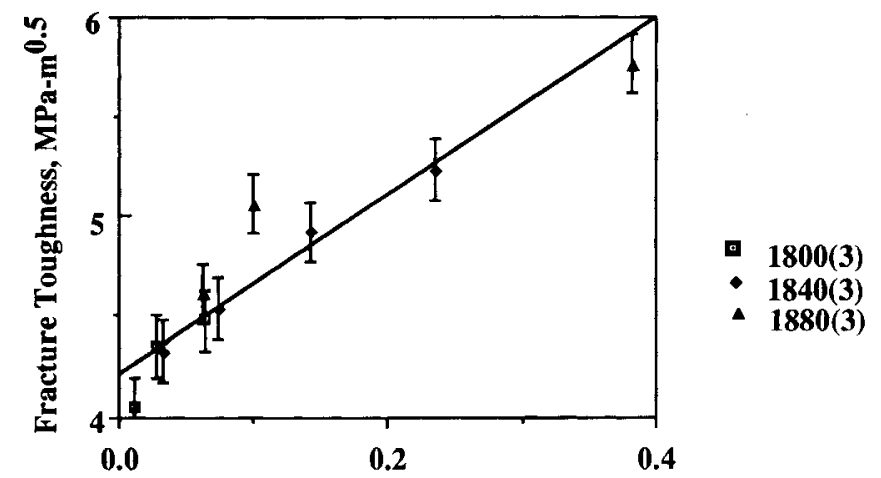

Area Fraction Bridging Grains

Fig. 13. Fracture toughness increases linearly as the area fraction of bridging grains increases. expansion coefficient of YAG is higher than that of the Y-SiAl-O-N glasses, the thermal expansion coefficient of the grain boundary phase which contains a large fraction of YAG would increase after crystallization. On the contrary, the thermal expansion coefficient of grain boundary phases which contain a large amount of N-phase would decrease after crystallization. The data in Fig. 6 suggest that the change in fracture toughness on crystallization is influenced by the change in thermal expansion coefficient of the grain boundary phase.

\section{Conclusions}

Thermal expansion mismatch between the grain boundary glass and the silicon nitride has been shown to influence the fracture toughness of silicon nitride. The thermal expansion mismatch causes residual stresses in the material, which interact with the advancing crack. Residual tensile stress at the grain boundary has been shown to increase the number of bridging grains and increase the fracture toughness. Although the thermal expansion coefficient of the grain boundary phase is not the only factor which affects the fracture behavior of silicon nitride ceramics, it has a large and predictable effect. Further studies on the effect of the chemistry of the sintering aid on microstructural development of the silicon nitride/glass interfaces and on the bond strengths between the silicon nitride and the glass would further improve understanding of the effect of the grain boundary phase on the fracture toughness of silicon nitride.

\section{References}

'P. F. Becher, "Microstructural Design of Toughened Ceramics," J. Am. Ceram. Soc., 74 [2] 255-69 (1991).

${ }^{2} \mathrm{M}$. Mitomo and S. Uenosono, "Microstructural Development during Gas Pressure Sintering of $\alpha-$ Silicon Nitride," J. Am. Ceram. Soc., 75 [1] 105 108 (1992).

${ }^{3}$ P. F. Becher, H. T. Lin, S. L. Hwang, M. J. Hoffman, and I-W. Chen, "The Influence of Microstructure on the Mechanical Behavior of Silicon Nitride Ceramics"; pp. 147-58 in Materials Research Society Symposium Proceedings, Vol. 287. Edited by I-W. Chen, P. F. Becher, M. Mitomo, G. Petzow, and T-S. Yen. Materials Research Society, Pittsburgh, PA, 1993.

${ }^{4}$ A. Pyzik and D. R. Beaman, "Microstructure and Properties of SelfReinforced Silicon Nitride," J. Am. Ceram. Soc., 76 [11] 2737-44 (1993)

${ }^{5}$ T. Hayashi and T. Y. Tien, "Formation and Crystallization of Oxynitride Glasses in the System Si,Al,Mg/O,N," Yogyo Kyokaishi, 94 [1] 44-52 (1983).

${ }^{6}$ D. A. Bonnell, "Determination of Crystallization Mechanisms and Correlation of Grain Boundary Morphology to Mechanical Properties in Silicon Nitride"; Ph.D. Thesis. University of Michigan, Ann Arbor, MI, 1986.

${ }^{7} \mathrm{C}$. M. Hwang, "The System of SiAlON-Y $\mathrm{Y}_{3} \mathrm{Al}_{5} \mathrm{O}_{12}$ and SiAION-Cordierite: Sintering and Grain Growth"; Ph.D. Thesis. The University of Michigan, Ann Arbor, MI, 1988.

${ }^{8} \mathrm{M}$. Wisnudel, "Solid-Liquid Reaction in the System SiAlON- $\mathrm{Y}_{3} \mathrm{Al}_{5} \mathrm{O}_{12}$ ", M.S. Thesis. University of Michigan, Ann Arbor, MI, 1991.

${ }^{9} \mathrm{Z}$. K. Huang and T. Y. Tien, "Solid-Liquid Reaction in the System $\mathrm{Si}_{3} \mathrm{~N}_{4}$ $\mathrm{Y}_{3} \mathrm{Al}_{5} \mathrm{O}_{12}-\mathrm{Y}_{2} \mathrm{Si}_{2} \mathrm{O}_{7}$ under 1 MPa of Nitrogen," J. Am. Ceram. Soc., 77 [10] 2763 66 (1994).

${ }^{10}$ S. D. Nunn, H. Honke, L. J. Gaukler, and T. Y. Tien, "Subsolidus Phase Relationships in Part of the System Si,AIMg/N,O," Am. Ceram. Soc. Bull, 57, 321 (1978).

${ }^{11}$ I. K. Naik and T. Y. Tien, "Subsolidus Phase Relations in Part of the System Si,Al, Y/N,O,"J. Am. Ceram. Soc., 62, 642 (1979).

${ }^{12}$ W.-Y. Sun, T. Y. Tien, and T.-S. Yen, "Sub-solidus Phase Relationships in Part of the System $\mathrm{Si}, \mathrm{Al}, \mathrm{Y}, \mathrm{N}, \mathrm{O}$ : The System $\mathrm{Si}_{3} \mathrm{~N}_{4}-\mathrm{AlN}-\mathrm{YN}-\mathrm{Al}_{2} \mathrm{O}_{3}-\mathrm{Y}_{2} \mathrm{O}_{3}$," J. Am. Ceram. Soc., 74 [11] 2753-58 (1991).

${ }^{13}$ I. Tanaka, G. Pezzotti, Y. Miyamoto, T. Okamoto, "Fracture Toughness of $\mathrm{Si}_{3} \mathrm{~N}_{4}$ and Its $\mathrm{Si}_{3} \mathrm{~N}_{4}$ Whisker Composite without Sintering Aids," J. Mater. Sci., 26, 208-10 (1991).

${ }^{14}$ G. H. Campbell, M. Rühle, B. J. Dalgleish, and A. G. Evans, "Whisker Toughening: A Comparison between Aluminum Oxide and Silicon Nitride Toughened with Silicon Carbide," J. Am. Ceram. Soc., 73 [3] 521-30 (1990).

${ }^{15}$ M. Taya, S. Hayashi, A. S. Kobayashi, and H. S. Yoon, "Toughening of a Particulate Reinforced Ceramic Matrix Composite by Thermal Residual Stress," J. Am. Ceram. Soc, 73 [5] 1382-91 (1990).

${ }^{16}$ H. Cai, N. P. Padture, B. M. Hooks, and B. R. Lawn, "Flaw Tolerance and Toughness Curves in Two-Phase Particulate Composites: SiC/Glass System," J. Eur. Ceram. Soc., 13, 149-57 (1994).

${ }^{17}$ A. G. Evans and M. Y. He, "Interface Debonding and Fiber Cracking in Brittle Matrix Composites," J. Am. Ceram. Soc., 72 [12] 2300-303 (1989).

${ }^{18}$ A. G. Evans and D. B. Marshall, "Overview No. 85: The Mechanical Behavior of Ceramics Matrix Composites." Acta Metall. 37 [10] 2567-83 (1989).

${ }^{19} \mathrm{M}$. Y. He and J. W. Hutchinson, "Kinking of a Crack out of an Interface," J. Appl. Mech., 56 [6] 270-78 (1989).

${ }^{20}$ A. G. Evans, A. H. Heuer, and D. L. Porter, "The Fracture Toughness of Ceramics," Proc. Int. Conf. Fract., 4th, I, 529-56 (1977). 
${ }^{21}$ R. A. Cutler and A. V. Virkar, "The Effect of Binder Thickness and Residual Stresses on the Fracture Toughness of Cemented Carbides," J. Mater. Sci., 20, 3557-73 (1985).

${ }^{22}$ P. G. Charalambides, H. C. Cao, J. Lund, and A. G. Evans, "Development of a Test Method for Measuring the Mixed Mode Fracture Toughness of Bimaterial Interfaces," Mech. Mater., 8, 269-83 (1990).

${ }^{23}$ T. Mura; pp. 184 in Micromechanics of Defects in Solids, 2 nd rev. ed. Martinus Nijhoff, Dordrecht, The Netherlands, 1987.

${ }^{24} \mathrm{C}$. H. Hsueh, "Sintering Behavior of Powder Compacts with Multiheterogeneities," J. Mater. Sci., 21, 2067-72 (1986).

${ }^{25}$ P. F. Becher, "Reinforced Ceramics Employing Discontinuous Phases"; pp. 475-83 in Ceramic Transactions, Vol. 19, Advanced Composite Materials. Edited by M. Sacks. American Ceramic Society, Westerville, OH, 1990.

${ }^{26}$ P. L. Swansson, C. J. Fairbanks, B. R. Lawn, and Y. Mai, "Crack-Interface Grain Bridging as a Fracture Resistance Mechanism in Ceramics: I, Experimental Study on Alumina," J. Am. Ceram. Soc., 70 [4] 279-89 (1987).

${ }^{27}$ S. J. Bennison and B. R. Lawn, "Role of Interfacial Grain-Bridging Sliding Friction in the Crack Resistance and Strength Properties of Non-Transforming Ceramics," Acta Metall., 37 [10] 2659-71 (1989).
${ }^{28}$ G. R. Anstis, P. Chantikul, B. R. Lawn, and D. B. Marshall, "A Critical Evaluation of Indentation Techniques for Measuring Fracture Toughness: I, Direct Crack Measurements," J. Am. Ceram. Soc., 4 [9] 533-38 (1981).

${ }^{29} \mathrm{~K}$. T. Farber and A. G. Evans, "Crack Deflection Processes--II. Experiment," Acta Metall., 31 [4] 577-84 (1983).

${ }^{30} \mathrm{P}$. F. Becher, S.-L. Hwang, and C.-H. Hsueh, "Using Microstructure to Attack the Brittle Nature of Silicon Nitride Ceramics," MRS Bull., 10 [2] 2327 (1995).

${ }^{31} \mathrm{~S}$. D. Nunn, Processing and Properties of SiC Whisker Reinforced $\mathrm{Si}_{3} \mathrm{~N}_{4}$ Ceramic Matrix Composites"; Ph.D. Dissertation. The University of Michigan, Ann Arbor, MI, 1991.

${ }^{32}$ W. Pompe and H. Kessler, "Internal Stresses in Silicon Nitride and Their Influence on Mechanical Behavior"; pp. 353-64 in Tailoring of Mechanical Properties of $\mathrm{Si}_{3} \mathrm{~N}_{4}$ Ceramics. Edited by M. J. Hoffman and G. Petzow. Kluwer Academic Publishers, Dordrecht, Netherlands, 1994.

${ }^{3}$ S. A. Bradley and K. R. Karasek, "Effect of Thermal and Stress Exposure on Grain Boundaries of Silicon Nitride," Ultramicroscopy, 29, 9-17 (1989). 